\title{
COMMENTARY
}

\section{Effects of non-neurological complications on traumatic brain injury outcome}

\author{
Kimberly S Meyer*1,2, Maxwell Boakye² and Donald W Marion' \\ See related research by Corral et al., http://ccforum.com/content/16/2/R44
}

\begin{abstract}
Traumatic brain injury (TBI) affects over 1.5 million

Americans annually and consumes a significant amount of healthcare dollars. Identification of complications and factors that impact recovery from TBI is important in improving outcome and allocating appropriate resources. Understanding the role of nonneurologic complications such as sepsis, acute kidney injury, and respiratory problems on TBI outcome and mortality is critical.
\end{abstract}

Traumatic brain injury (TBI) is the leading cause of death and disability in those between the ages of 1 and 45 years, so the recognition and effective treatment of conditions that adversely affect TBI outcomes are critically important. The study by Corral and colleagues [1] discusses the impact of certain non-neurologic complications on the outcome of TBI.

The key factors impacting acute mortality, such as the Glasgow Coma Score, pupil abnormalities, and imaging findings, are well-established. The mortality rate for TBI patients during their acute care at a major university trauma center was recently found to be $15 \%$, with the highest rate for those with penetrating injury or age $>65$ years (Meyer and colleagues, unpublished data). In addition, anatomical scoring systems have been developed and implemented, such as the Injury Severity Score, which have significantly improved our ability to predict mortality early after the injury [2-6].

The impact of non-neurological complications on TBI outcomes is less clear. With a few exceptions, the rates of these complications in Corral and colleagues' sample [1] are congruent with previously reported incidences, as

\footnotetext{
*Correspondence: ksmeyer21@gmail.com

${ }^{2}$ Center for Advanced Neurosurgery, University of Louisville, Louisville, KY 40202 , USA

Full list of author information is available at the end of the article
}

well as our own experience. The rates of respiratory infections in TBI patients have declined over the past 10 years, from $88 \%$ in 2001 [7] to $68 \%$ in the study by Corral and colleagues [1], likely secondary to increased diligence at preventing ventilator-associated pneumonia. Contrary to previous studies, but consistent with our own recent findings (Meyer and colleagues, unpublished data), hypotension was not found to be an independent predictor of death. However, the $8 \%$ incidence of acute kidney injury (AKI) found in the study by Corral and colleagues [1] was much higher than the $1.5 \%$ reported by Shirmer-Mikalsen and colleagues [8] for a similar cohort. At our trauma center we have seen a decrease in the development of AKI, which may, in part at least, be due to a transition from the use of mannitol, a potentially nephrotoxic osmotic diuretic, to hypertonic saline for the treatment of elevated intracranial pressure. Moreover, increased age may have been a confounding variable contributing to the high incidence of AKI in the Corral and colleagues study.

An unusually high incidence of sepsis also was observed in the study by Corral and colleagues [1]. At a rate of $75 \%$, this incidence is much higher than that seen at our trauma center or in other reported series. Selassie and colleagues [9] reported a sepsis rate of 16 per 1,000 patients $(<1 \%)$, although this sample included all TBI severities. As with the current study, Selassie and colleagues found that sepsis was associated with an increased risk of in-hospital deaths. Others describe sepsis rates in severe TBI of 6\% [8]. The significant variance in published sepsis rates is likely multi-factorial, and differences in sepsis-reporting criteria may play a role.

This study highlights the medical complexity of the acute care of those with TBI, and illustrates important risk factors associated with mortality in a well-defined cohort. However, reliable conclusions about the most common causes of non-neurologic mortality may not be possible because the authors did not address the differences in observed mortality versus expected mortality, thereby accounting for the intentional withdrawal of care. In addition, multiple complications co-exist in many TBI 
patients, and particularly those with severe TBI. The impact of multi-system dysfunction should be further investigated.

\section{Competing interests}

The authors declare that they have no competing interests.

\section{Author details}

'Defense and Veterans Brain Injury Center - Rockville, MD 20852, USA. ${ }^{2}$ Center for Advanced Neurosurgery, University of Louisville, Louisville, KY 40202, USA.

\section{Abbreviations}

$\mathrm{AKI}$, acute kidney injury; TBI, traumatic brain injury.

Published: 23 May 2012

\section{References}

1. Corral L, Javierre CF, Venturan JL, Marcos P, Herrero Jl, Mañez R: Impact of non-neurological complications in severe traumatic brain injury outcome. Crit Care 2012, 16:R44.

2. Demetriades D, Kuncir E, Murray J, Velmahos GC, Rhee P, Chan L: Mortality prediction of head Abbreviated Injury Score and Glasgow Coma Scale: analysis of 7,764 head injuries. J Am Coll Surg 2004, 199:216-222.

3. Demetriades D, Kuncir E, Brown CV, Martin M, Salim A, Rhee P, Chan LS: Early prediction of mortality in isolated head injury patients: a new predictive model. J Trauma 2006, 61:868-872.
4. Foreman BP, Caesar RR, Parks J, Madden C, Gentilello LM, Shafi S, Carlile MC Harper CR, Diaz-Arrastia RR: Usefulness of the abbreviated injury score and the injury severity score in comparison to the Glasgow Coma Scale in predicting outcome after traumatic brain injury. J Trauma 2007, 62:946-950.

5. Ronning PA, Pedersen T, Skaga NO, Helseth E, Langmoen IA, Stavem K: External validation of a prognostic model for early mortality after traumatic brain injury. J Trauma 2011, 70:E56-61.

6. Timmons SD, Bee T, Webb S, Diaz-Arrastia RR, Hesdorffer D: Using the abbreviated injury severity and Glasgow Coma Scale scores to predict 2-week mortality after traumatic brain injury. J Trauma 2011, 71:1172-1178.

7. Vitaz TW, Mcllvoy L, Raque GH, Spain D, Shields CB: Development and implementation of a clinical pathway for severe traumatic brain injury. J Trauma 2001, 51:369-375.

8. Schirmer-Mikalsen K, Vik A, Gisvold SE, Skandsen T, Hynne H, Klepstad P: Severe head injury: control of physiologic variables, organ failure, and complications in the intensive care unit. Acta Anaes Scand 2007 51:1194-1201.

9. Selassie AW, Fakhry SM, Ford DW: Population-based study of the risk of in-hopsital death after traumatic brain injury: the role of sepsis. J Trauma 2011, 71:1226-1234.

doi:10.1186/cc11311

Cite this article as: Meyer KS, et al.: Effects of non-neurological complications on traumatic brain injury outcome. Critical Care 2012, 16:128. 